\title{
EL DERECHO A LA LIBERTAD DE EXPRESIÓN: ¿¿UNA LIMITANTE AL PODER ESTATAL? (A PROPÓSITO DEL DIÁlOGO INTERSUBJETIVO EN UNA SOCIEDAD DEMOCRÁTICA)*
}

\section{Hugo Vega ZAMORA ${ }^{* *}$}

RESUMEN: El presente trabajo expondrá los presupuestos del derecho a la libertad de expresión como parte integrante del diálogo intersubjetivo en las esferas comunicativas, y también cómo su configuración como derecho importa un límite al poder estatal en el denominado Estado democrático de Derecho, desde la óptica del importante trabajo de Jürgen Habermas. Para ello se reflexionará sobre el alcance de la libertad de expresión y encuadrarla no solo dentro de las clásicas libertades negativas, sino que repensar su alcance como una libertad de carácter positivo, para luego contrastar el resultado de tal reflexión en el contexto democrático procedimental que nos ofrece la teoría habermasiana, y los alcances de la misma tanto en la teoría política y jurídica interna como en el Derecho internacional.

PALABRAS CLAVE: Derecho a la libertad de expresión - democracia diálogo intersubjetivo - derechos fundamentales - Estado democrático de Derecho - Habermas.

\section{THE RIGHT TO FREEDOM OF EXPRESSION: A LIMITING RIGHT ON STATE POWER? (ABOUT THE DIALOGUE IN A DEMOCRATIC INTERSUBJECTIVE SOCIETY)}

ABSTRACT: This paper is about the budgets of the right to freedom of expression as part of the dialogue in the intersubjective areas related to communication, and also how its configuration as a right sets a limit on state power in the so-called democratic state of law, from the perspective of the important work of Jürgen Habermas. It will be analyzed on the

\footnotetext{
* Fecha de recepción: 20 de septiembre de 2011.

Fecha de aceptación: 18 de agosto de 2012.

** Abogado. Licenciado en Ciencias Jurídicas, Universidad Católica del Norte. Investigador adjunto, Universidad Diego Portales. Correo electrónico hugovegazamora@gmail.com. Agradezco las sugerencias y comentarios realizados por el doctor Mauro Basaure (Univ. Andrés Bello) y las importantes precisiones realizadas por el abogado asistente del Tribunal Constitucional Sr. Guillermo Stange.
} 
scope of freedom of expression and fit it not only within the traditional negative liberties but re-thinking its scope as a freedom of a positive nature, and then compare the results of this analysis on the procedural democratic context offered by the Habermasian theory, and the scope of it including the domestic and political legal theory and International Law.

KEY WORDS: Right to freedom of expression - democracy - intersubjective dialogue - fundamental rights - a democratic state of law - Habermas.

El día 5 de febrero del año 2001, la Corte Interamericana de Derechos Humanos (en adelante, CIDH) falló en contra del Estado chileno, en el marco de la censura estatal impuesta a la exhibición pública de la película La última tentación de Cristo. En efecto, la CIDH estimó que la decisión de la Corte de Apelaciones de Santiago (y confirmada luego por la Corte Suprema) de prohibir la exhibición de tal película -basada en una supuesta afrenta a la honra de Jesucristo y de la Iglesia Católica- vulneraba al derecho de la libertad de pensamiento y de expresión que todo Estado que ha suscrito la Convención Interamericana de Derechos $\mathrm{Hu}-$ manos debe no solo promover y respetar, sino que además obliga a todos los Estados-parte de tal Convención a adecuar su ordenamiento jurídico interno para que efectivamente se garantice tal derecho ${ }^{1}$.

La importancia de tal fallo no solo se limita al ámbito netamente jurídico, sino que tuvo importantes repercusiones a nivel social. La censura previa -cuyo origen se remonta a los enclaves más autoritarios del ordenamiento jurídico fundado en la Constitución Política de 1980- fue una importante fuente de limitaciones a la naciente democracia de la primera mitad de los años 90 en nuestro país. Películas como la ya nombrada obra de Martin Scorsese, u otras como Pepi, Lucy, Bom y Otras Chicas del Montón de Pedro Almodóvar, o libros como Los secretos de Fra-Fra de María Inés Soto, o El libro Negro de la Justicia Chilena, de la periodista Alejandra Matus, por nombrar algunos, fueron objeto de la censura estatal, impidiéndose su exhibición o comercialización por el poder coactivo del Estado. El fallo vino a revertir esta situación (aunque técnicamente limitando la sanción a la denominada censura cinematográfica) obligando al Estado de Chile a realizar sendas modificaciones al ordenamiento jurídico -la que incluyó una modificación al artículo 19 n 25 de la Constitución

Corte Interamericana de Derechos Humanos (CIDH) 5 de febrero de 2001. Olmedo Bustos y otros v. Chile. Disponible en http://www.corteidh.or.cr/docs/casos/articulos/Seriec_73_esp.pdf [fecha de consulta: 3 de abril de 2011]. 
inclusive, a propósito de las creaciones artísticas- las cuales se llevaron a cabo en los primeros ańos del nuevo milenio ${ }^{2}$.

Sin lugar a dudas uno de los pilares doctrinales en la construcción del concepto actual de Estado de Derecho es el respeto a los derechos fundamentales. ¿Por qué, entonces, se ha dado la situación de que la libertad de expresión, uno de los derechos más importantes en el contexto de las luchas sociales tanto de los individuos como de los grupos minoritarios, ha sido siempre relegada a un segundo plano, o inclusive, derechamente vulnerada por los Estados? ¿Es realmente un límite al ejercicio del poder soberano estatal, en los términos de un Estado democrático de Derecho? Tales preguntas, resultantes de un examen de los diversos factores que influyen en cómo se producen las políticas de delimitación del poder estatal y de su vinculación con la sociedad multicultural que como factum innegable se nos presenta, serán el hilo conductor de la presente exposición.

Para dar respuestas a las interrogantes planteadas supra es preciso (I) delimitar qué debe entenderse -necesariamente- por derecho a la libertad de expresión, para así obtener una noción de su naturaleza. Luego, debido a la importancia que ofrece la interrogante de por qué históricamente se ha restringido la libertad de expresión a favor del poder estatal, es menester (II) resaltar el tratamiento que ha tenido tal derecho en torno a una concepción democrática de Estado, por un lado; y, por otro, en el contexto de una noción de Estado de democracia limitada o inexistente. Enseguida intentaré (III) dilucidar de qué forma tal derecho es una limitante al poder estatal, sirviéndome para este punto principalmente de la postura de dos pensadores alemanes, cuyas obras han sido de la más alta importancia en el campo del pensamiento político: Jürgen Habermas y Otfried Höffe.

La libertad de expresión tiene su historia entrecruzada con el liberalismo. John Locke se refiere a la libertad de expresión en su Ensayo sobre la Tolerancia (1666), señalando que las opiniones -en general- deben ser toleradas, pero que el magistrado puede prohibir su ejercicio cuando estas perturben al gobierno ${ }^{3}$, derivado ello de la limitación a la propia libertad que los hombres pactaron para el establecimiento de una sociedad

\footnotetext{
2 González Morales, Felipe (2006) "Censura judicial y libertad de expresión: Sistema interamericano y derecho chileno". En Libertad de Expresión en Chile, ed. Felipe González. Santiago: Facultad de Derecho de la Universidad Diego Portales, pp. 32-42.

3 Locke, John (1999) "Ensayo sobre la tolerancia". En Ensayo y Carta sobre la Tolerancia. Trad. Carlos Mellizo. Madrid: Alianza Editorial, pp. 30-31.
} 
política que proteja a su persona y sus bienes ${ }^{4}$. En efecto, así considera$\mathrm{da}$, es inmediatamente clasificable como una de las libertades básicas del pensamiento liberal, y como su delimitación gira en torno al objeto de la misma, es posible ya subdividirla en atención al mismo. Así -en el amplio espectro de las ciencias sociales (y no solo del Derecho) - es posible subclasificar a la libertad de expresión en libertad de prensa, libertad artística, libertad de opinión y libertad religiosa.

El derecho a la libertad de expresión correspondería, por tanto, como una manifestación de la libertad entendida en términos negativos, tal y como Isaiah Berlin la propuso: "En este aspecto -señala Berlin- la libertad politica es, simplemente, el espacio en el que un hombre puede actuar sin ser obstaculizado por otros" $"$.

Otros autores que adhieren al contractualismo liberal, como el importantísimo John Rawls, no creen que en el estado de naturaleza existan derechos naturales, sino que más bien creen en una justicia procedimental pura: el procedimiento correcto define al resultado correcto, partiendo de la premisa de la igualdad de los sujetos participantes ${ }^{6}$. Frente a este procedimiento, los hombres poseen ciertas capacidades humanas básicas -fuente de los principios políticos de una sociedad liberal y pluralista- y entre las que destaca, según Martha Nussbaum, una capacidad de control sobre el propio entorno político, desprendiéndose la protección que se le debe otorgar a la libertad de expresión y de participación ${ }^{7}$.

Dentro del liberalismo, por tanto, no es posible encontrar un consenso en torno al origen del derecho a la libertad de expresión. Así, puede corresponder a un derecho natural (Locke) o la protección de una de las capacidades básicas del ser humano (Rawls, Nussbaum). Sin embargo, parece desprenderse de toda visión liberal que la libertad de expresión tiene una importancia capital para que un sujeto ("ciudadano") pueda participar dentro de su comunidad, expresando deseos, creencias, preferencias u opiniones. Aunque no exista consenso sobre su origen en la misma tradición que lo vio nacer, es posible definir tal derecho de un modo amplio: es el derecho basado en la libertad de cada sujeto a exteriorizar su propio pensamiento.

El problema de tan amplia definición, empero, pasa más bien por la necesidad de encontrar una frontera entre "lo que se protege" y "lo protegido". Es por ello que la pregunta de lo que entendemos por libertad de

\footnotetext{
4 Nussbaum, Martha C. (2007) Las Fronteras de la Justicia. Trad. Ramón Villa Vernis y Albino Santos Mosquera. Barcelona, Paidós, p. 61.

5 Berlin, Isaiah (2004) "Dos Conceptos de Libertad". En Sobre la Libertad. Ed. H. Hardy, y trad. J. Bayón. Madrid: Alianza Editorial, p 208.

6 Rawls, John (2004) "La justicia como imparcialidad", en John Rawls, Teoría de la Justicia, $2^{a}$ ed. en español. Trad. María Dolores González (México D.F.: Fondo de Cultura Económica, pp. 17-61.

$7 \quad$ Nussbaum (2007) 88-89.
} 
expresión pasa, necesariamente, por responder la siguiente: ¿El derecho a la libertad de expresión protege la oportunidad de emitir una obra, opinión o creencia; o también protege, en términos amplios, a la obra, opinión o creencia?

La respuesta a tal interrogante pasa por una delimitación conceptual, y creo que la CIDH, al fallar en el caso de La Última Tentación de Cristo, fue clave: contextualizó la noción de libertad de expresión (considerando 64) no solo como un derecho con una faz subjetiva, típicamente liberal, sino que más bien como un derecho bifronte: la libertad de expresión posee además una faz colectiva o social, que se traduce en "(...) el derecho y la libertad de buscar, recibir y difundir informaciones e ideas de toda índole" 8 .

El juego propuesto, de la libertad de emitir una opinión (sea en el ámbito que sea) y la libertad de recepción de dicha opinión por parte de la sociedad es, a mi entender, el punto neurálgico para comprender que la importancia del derecho en cuestión radica en su carácter formal; y que por ello es distinto a otros derechos fundamentales. Así, en el derecho a la vida o en el derecho a la propiedad, o en el derecho a la libertad personal, el ejercicio de los mismos importa necesariamente la sustantividad de estos. En la libertad de expresión, en cambio, contenido y oportunidad de ejercitarlo se separan, ya que lo que se protege es precisamente la oportunidad, mientras que el contenido del derecho (la expresión que se intenta difundir) no debiera importar -en el contexto teórico de una democracia procedimental pura- sino solo a quien difunde tales expresiones, a menos -claro- que estas colisionen con otros derechos fundamentales (por ejemplo, el honor, la honra o la vida privada), caso en el cual el órgano estatal que vela por la resolución de los conflictos intersubjetivos será el que decida si existe o no tal colisión.

Pero ¿la existencia de esta desavenencia no significaría que el contenido del derecho a la libertad de expresión sí importa? Claro que importa, pero no en cuanto a ejercicio del mismo, sino en cuanto a las limitaciones que puede sufrir el contenido. El derecho a la libertad de expresión se traduce de esta forma en un derecho más bien de orden participativo dentro del contexto social y multicultural, o dicho de otro modo, una forma de participación necesaria del emisor en las esferas de comunicación intersubjetivas. Una opinión, una obra o incluso una creencia puede ser no tolerada por sectores de la sociedad en atención a sus propias creencias o preferencias, pero jamás podría ser censurada la oportunidad de emitir una opinión, de realizar una obra o adscribir a una creencia por la vía de la

8 ZÚNiga FAJURI, Alejandra (2006) "La libre formación del pensamiento en el caso 'La Última Tentación de Cristo'”. En Libertad de Expresión en Chile, ed. Felipe González. Santiago: Facultad de Derecho de la Universidad Diego Portales, pp. 292- 294. 
coacción estatal sin incurrir en un ataque flagrante a dicho derecho 9 . Y la única forma que existiese un conflicto entre la opinión, obra o creencia se traducirá necesariamente en una colisión, o derechamente en una lesión a un derecho fundamental, caso en el cual será el Estado, a través de sus órganos jurisdiccionales y en uso de sus facultades coactivas, el que deba ponderar tal colisión o daño ${ }^{10}$.

Jürgen Habermas, con acierto, ha entendido la importancia de los derechos de participación y de comunicación como necesarios para garantizar la autonomía pública de los ciudadanos, y por tanto, su participación en la vida social. Autonomía privada y pública se presuponen mutuamente en esta clase de derechos. Así, el autor alemán señala que “(...) sin los derechos privados clásicos, en particular una igual libertad de acción, no existiría tampoco ningún medio para la institucionalización jurídica de aquellas condiciones bajo las cuales los ciudadanos puedan participar en la praxis de su autodeterminación"11. De esta forma, se entiende la libertad de expresión como una parte de la libertad positiva de Berlin, vale decir como autodeterminación del individuo ${ }^{12}$, y que muchos han entendido como libertad republicana ${ }^{13}$.

Por tanto, la respuesta a la interrogante planteada se traduce en considerarlo no como un derecho fundamental sustantivo, sino más bien como un derecho politico o de participación subjetivo, procedimental y con

9 Así lo han entendido los Estados que suscribieron la Convención Interamericana de Derechos Humanos, la cual, en su artículo 13.2 señala "El ejercicio del derecho previsto en el inciso precedente (libertad de expresión) no puede estar sujeto a previa censura sino a responsabilidades ulteriores, las que deben estar expresamente fijadas por la ley (...)".

10 Se hace interesante que la regulación normativa de la oportunidad del ejercicio de tal derecho aparezca establecida bajo la fórmula legítimo ejercicio. En efecto, si bien el derecho positivo puede crear límites al ejercicio de un derecho (en este caso legítimo, vale decir bajo una forma prescrita ex ante por el ordenamiento jurídico), la configuración que ofrezco -al señalar que el ejercicio corresponde a la oportunidad- no da cabida a tal fórmula positiva: todo ejercicio del derecho a la libertad de expresión se manifiesta en un actuar formal, sin necesidad de imposición o exclusión coactiva de un determinado contenido. En definitiva, ejercicio legitimo será equivalente a oportunidad, y siempre el ejercicio ha de ser legítimo. El contenido o producto de tal ejercicio, en cambio y por lo ya señalado supra, puede ser sujeto a estimación jurídica.

11 Habermas, Jürgen (2000-a) “Acerca de la legitimación basada en derechos humanos”. En J. Habermas, La constelación posnacional. Ensayos Politicos, trad. Pere Fabra et al. Barcelona: Paidós, p. 152. Además, Habermas señala que "Los derechos fundamentales, tanto los que garantizan libertades individuales como los de participación política, fundamentan el estatuto del ciudadano, estatuto que entretanto se ha vuelto autorreferencial en la medida que habilita a los ciudadanos unidos democráticamente a conformar su propio estatus mediante la autolegislación". Habermas, Jürgen (2000-b) "La constelación posnacional y el futuro de la democracia”. En J. Habermas, La constelación posnacional. Ensayos Politicos, trad. Pere Fabra et al. Barcelona: Paidós, p. 103.

12 BERLIN (2004) 217-220.

13 Beade, Ileana P. (2009) "Consideraciones acerca de la concepción kantiana de la libertad en sentido político", Revista de Filosofía 65, doi: 10.4067/S0718-43602009000100002, p. 25 41. 
un contenido moral neutro, necesario absolutamente para que el diálogo intersubjetivo a nivel social (sea en las esferas de comunicación formales, sea en las informales) prospere: el derecho a expresar toda opinión, obra o creencia que se estime como necesaria dentro del marco intersubjetivo (formal o informal) en que se desenvuelve la persona que ejerce tal derecho.

\section{II}

Sin lugar a dudas ha existido un conflicto patente entre las libertades individuales en general con la noción de poder estatal. Felipe González señala al respecto que "(...) en la medida en que se transita hacia regímenes democráticos, dicha forma de censura [censura administrativa] tiende a desaparecer" ${ }^{14}$. Ivo Duchacek, para reflejar la -a veces- excesiva regulación que recae sobre el derecho a la libertad de expresión en los gobiernos no democráticos señaló, con absoluta razón, que “(...) [l]a actitud de los autoritarios respecto a la libertad de expresión refleja síntomas de esquizofrenia"15. La censura en los Estados totalitarios o tiránicos suele ser desmedida, mientras que en los Estados democráticos parece disminuir, o incluso, desaparecer. Esa misma idea ha sido la tónica de las constituciones políticas nacionales, tengan o no un origen democrático, al imponer toda suerte de regulaciones al ejercicio o al producto de la libertad de expresión ${ }^{16}$. ¿A qué se debe tan singular fenómeno?

La respuesta, creo, está en la limitación que sufre el poder político en un gobierno democrático respetuoso de los derechos humanos. En un Estado autoritario es difícil pensar que una opinión, obra o creencia no oficial pueda entrar en aquel espacio público que Habermas ha identificado como necesario para que exista una pluralidad de opiniones e ideas que favorezcan la toma de decisiones, debido a -como lo señala el mismo autor- la configuración de este espacio necesario está expuesta “(...) a los efectos de represión y exclusión de la desigual distribución del poder social, del poder estructural y a la comunicación sistemática

\footnotetext{
14 González Morales (2006) 11.

15 Duchacek, Ivo (1976) Derechos y libertades en el mundo actual, trad. Octavio Monserrat Zapater. Madrid: Instituto de Estudios Políticos, p. 287.

16 Duchacek clasifica al derecho a la libertad de expresión en absoluto o relativo, dependiendo si su defensa constitucional es irrestricta, o bien, es limitada. La conclusión a la que llega el autor, luego del examen realizado, es que las diversas Constituciones o interpretaciones jurisprudenciales realizadas de ellas mismas, incluyen mecanismos de limitación de la libertad de expresión. Duchacek (1976) 293 - 301. Vgr., la Constitución Política de la República de Chile, que en su tenor original (antiguo artículo $8^{\circ}$ ), proscribía a todo movimiento de orientación marxista ("lucha de clases") por ser contrario al ethos constitucional.
} 
distorsionada" 17 , y los cuales se intensifican en el caso de democracias imperfectas o derechamente, en dictaduras unipersonales. Así, tanto las restricciones al uso de internet en China o en Cuba, como la quema de libros, el cierre de los mass media, y la prohibición de música considerada contraria al régimen militar en el Chile del segundo lustro de los años 70 son claros ejemplos de vulneración a la libertad de expresión en regímenes totalitarios.

Si la limitación a la libertad de expresión aparece como un rasgo característico de la falta de democracia, es necesario responder ahora el porqué también se limita la libertad de expresión en una democracia, incluso en aquellas que aparecen como respetuosas de los derechos humanos. En efecto, parece contraproducente limitar las libertades del hombre en un régimen que se supone las protege. La respuesta, en gran medida parte de la distinción que he realizado. Así, puedo estimar que la limitación de la libertad de expresión en su vertiente formal es condenable absolutamente: la sola imposición de una limitante a este derecho vulneraría absolutamente los parámetros en que la democracia procedimental transita, y que será el tema a abordar infra. Lo que sí puede limitarse, sin por ello vulnerar a la libertad de emitir una expresión es el producto de la oportunidad, vale decir, la obra, opinión o creencia.

La doctrina constitucionalista ha intentado dilucidar este problema basándose en la noción de colisión entre derechos fundamentales. Así, cuando un constituyente establece los derechos fundamentales que en el ordenamiento jurídico deben primar, no existe conflicto entre ellos in abstracto, pero en los hechos es posible que sí. En definitiva, es posible limitar el producto de la libertad de expresión en el contexto de un Estado Constitucional de Derecho cuando tal producto de alguna forma entra en conflicto con otros derechos fundamentales individuales o colectivos ${ }^{18}, \mathrm{y}$ en tales casos, será decisión del juez establecer si existe o no conflicto.

\section{III}

Tal vez uno de los mayores méritos de las sociedades modernas es haber logrado que el poder político del Estado -que se consideraba emanado directamente de Dios y que por ello era ilimitado en las manos del soberano absoluto- fuese limitado por el derecho y su origen encontrase

17 Habermas, Jürgen (2005) "Política deliberativa". En J. Habermas, Facticidad y Validez. Sobre el derecho y el Estado democrático de derecho en términos de teoría del discurso, $4^{a}$ edición, trad. Manuel Jiménez Redondo. Madrid: Trotta, p. 385.

18 Lovera Parmo, Domingo (2006) "El interés público como estándar. Libertad de Expresión y Vida Privada". En Libertad de Expresión en Chile, ed. Felipe González. Santiago: Facultad de Derecho de la Universidad Diego Portales, pp 57-59. 
residencia en manos de la comunidad de ciudadanos. $Y$ ese proceso se perfeccionó aun más cuando las sociedades empezaron a reconocer que ciertos derechos, inherentes a la calidad de ser humano y, por ello, con un contenido altamente moral, necesariamente constituyen barreras al poder estatal.

Otfried Höffe, al respecto, señala que existe una diferencia entre los derechos denominados como humanos y los derechos fundamentales, ya que estos son normas jurídicas con una vigencia limitada a un determinado ordenamiento jurídico nacional, mientras que los derechos humanos sin más, corresponden a postulados ético-políticos con una validez general. La diferencia radica en la necesidad de reconocimiento estatal de los mismos: una norma jurídica positiva circunscrita a un determinado Estado-nación será un límite mucho más efectivo ya que será parte del ordenamiento jurídico interno, y por tanto, si el Estado se configura como estado de derecho, los derechos fundamentales serán límite positivo para el ejercicio del poder estatal ${ }^{19}$.

Pero ¿será tan necesaria la incorporación de un determinado derecho subjetivo al ordenamiento jurídico nacional para que se transforme así en un límite al ejercicio del poder estatal? Recordemos que el Estado democrático de Derecho, según el planteamiento habermasiano, se traduce en la constante limitación del Derecho al poder republicano ${ }^{20}$. De esta forma, se asegura que la sociedad se separe del Estado, y que los derechos de la misma frente al poder estatal se vean resguardados por el ordenamiento jurídico. En principio, por tanto, el planteamiento de Höffe respecto a la necesidad de positivar los derechos humanos es necesario bajo el concepto de estado de derecho: así el poder político estatal se verá limitado por reglas positivas necesarias, y dentro de las cuales se encuentran los derechos elevados a la categoría de fundamentales dentro de las fronteras estatales.

Todo esto vale para el derecho a la libertad de expresión en los términos ya expuestos. Sin embargo, es preciso plantear algunos problemas relacionados para llegar más a fondo al problema de si la libertad de expresión es un límite al poder estatal. Intentaré defender las siguientes tesis: $i)$ no es necesario positivar el derecho a la libertad de expresión en un Estado democrático de Derecho y ii) internacionalmente es necesario introducir en un orden positivo a tal derecho, para efectos de garantizar su respeto dentro de los Estados.

19 HöFfe, Otfried (2003) "Estrategias de la Justicia Política. Una visión panorámica”. En O. Höffe, Justicia Politica: Fundamentos para una filosofía critica del Derecho y del Estado. Barcelona: Paidós, pp. 182 y ss.

20 "El derecho es solamente el medio organizativo de la administración. Protege a la sociedad formada por individuos privados frente al estado al encauzar jurídicamente la relación entre ambos" Habermas (2000-B) 86. 
i) Tal y como fue expuesto anteriormente, existen ciertos Estados, generalmente democracias imperfectas, dictaduras autoritarias o gobiernos teocráticos, en los cuales una limitación al derecho de libertad de expresión es necesaria para garantizar o el orden (o mejor dicho la imposición de cierto orden), o la supremacía de una determinada opinión o creencia, estimada como verdad estatal, frente a otras. Así, Duchacek sostiene que cierto grupo de constituciones, y en la que se engloba a una mayoría, ponen en énfasis la necesidad de que "la libertad de expresión política o no política queda a menudo en inferioridad frente a otros valores sociales", lo cual no deja de ser cierto en los casos ya señalados, e incluso en las democracias consideradas como sanas, reflejándose tal idea en los ordenamientos jurídicos nacionales ${ }^{21}$.

Tal idea de derecho a la libertad de expresión limitada ex ante es contraria a la política deliberativa tal y como la ha propuesto Habermas. En un Estado en que la libertad de emitir expresión u opinión se vea limitada por estándares morales sostenidos por sus gobernantes se vulnera gravemente la esencia de este derecho, y por tanto, la participación ciudadana en la toma de decisiones. En efecto, la autonomía privada de las personas se vulneraría drásticamente en pos de un límite artificial impuesto, mientras que la autonomía pública sucumbiría por la falta del espacio necesario para que se desarrolle.

Este problema creo que es importante. En Facticidad y Validez y en otras obras posteriores, Habermas plantea la necesidad de que el sistema de los derechos exija la realización simultánea y complementaria de ambos tipos de autonomía, para que el objetivo de una política deliberativa basada y reglada únicamente en su aspecto formal sea una realidad. La importancia de ambos tipos de autonomía en torno a la idea de discurso se basa, necesariamente en la operatividad de la comunicación (institucionalizada por los derechos humanos) para la formación de una voluntad política racional $^{22}$.

Una censura previa -vale decir anterior a la entrada de la creencia, opinión u obra al contexto social para que sean los mismos habitantes quienes decidan su suerte-, como la que el Estado de Chile a través de sus órganos judiciales realizó (y cuya breve descripción realicé supra), sin lugar a dudas acarrearía una anormalidad en las condiciones equitativas del diálogo necesario dentro de la teoría del discurso al vulnerarse las denominadas por Robert Alexy, siguiendo algunas de las ya propuestas en el ámbito político-deliberativo por Joshua Cohen, como reglas de tipo procedimentales (o especificas) en la realización del mismo. Tales normas procedimentales -inherentes a todo sistema discursivo- son las reglas de 
participación ("todo hablante puede participar del discurso"), las reglas de contenido ("todos pueden cuestionar cualquier aserción", "todos pueden introducir cualquier aserción en el discurso" y "todos pueden expresar sus deseos, opiniones y necesidades), y las reglas de exclusión de la coacción ("nadie puede ser impedido por coacción -sea dentro o fuera del discurso- a ejercer las reglas de contenido y de participación”) ${ }^{23}$.

Por tanto, en el ámbito interno de un Estado democrático que cumple con todos los presupuestos necesarios para que el derecho a la libertad de expresión surja como natural consecuencia del diálogo intersubjetivo, no es necesaria su introducción en el ordenamiento jurídico positivo, toda vez que es inherente a la democracia procedimental misma. El Estado, para considerase democrático debe respetar los derechos de opinión y participación en la sociedad, porque de lo contrario su condición de democrático sería ilusoria. Los derechos de opinión y participación en el plano intersubjetivo (como el de la libertad de expresión) son inherentes a la democracia procedimental, protegida esta a través de los derechos fundamentales sustantivos ${ }^{24}$.

ii) En el marco interno, y como ya se señaló anteriormente, Höffe es partidario de positivar a los derechos humanos, para que cobren fuerza vinculatoria y coactiva como derechos fundamentales, limitando de una forma efectiva al Estado. Sin embargo, ¿qué sucedería si un determinado Estado democrático de Derecho, no respetara (en su ámbito interno) a la libertad de expresión en su faz jurídica, vale decir, como un derecho? Habermas y Höffe, sin más, sostendrían una postura a favor de los derechos humanos como estándares normativos vinculantes no positivados, pero que de alguna forma deben ser respetados por los Estados, como condición necesaria para constituir una justicia política ${ }^{25}$. Y es el Derecho internacional quien cumple una misión supletoria en este sentido.

En el espectro internacional sucede algo similar a lo planteado por Höffe. Las convenciones y tratados internacionales suelen incorporar cláusulas generales en donde se reconocen como fundamentales a ciertos derechos, sean liberales o sociales, que se entienden como indispensables para el respeto de la dignidad del ser humano dentro del marco estatal. $\mathrm{Y}$ tales tratados o convenciones también ocupan un lugar privilegiado en

23 Alexy, Robert (2004) "Una concepción teórico-discursiva de la razón práctica”. En R. Alexy, El concepto y la validez del derecho, trad. Jorge M. Seńa. Barcelona: Gedisa Editorial, pp. 137-138; Habermas (2005) 384.

24 "El buscado nexo interno, entre derechos humanos y soberanía popular consiste, por tanto, en que los derechos humanos institucionalizan las condiciones comunicativas para la formación de una voluntad política racional.” HaBERMas (2000-A) I 52.

25 Habermas, Jürgen (2010) "The concept of human dignity and the realistic utopia of human rights" Methaphilosophy v. 41-4, p. 470; Habermas (2000 a) 153; Höffe, Otfried (2010) La justicia en un mundo globalizado. Santiago: Universidad Adolfo Ibáñez, p. 17; HöffE (2003) $183-186$. 
el ordenamiento jurídico nacional, toda vez que se incorporan al derecho interno una vez ratificado por el Estado-parte ${ }^{26}$. Siguiendo el ejemplo con el que inicié este ensayo, el Estado chileno en el caso de la película de Scorsese cometió una falta a la Convención Interamericana de Derechos Humanos, en específico al artículo 13 de la misma, que aboga por la libertad de pensamiento y expresión en términos amplios, al mantener una legislación interna que legitima la censura previa.

La posición de Höffe, de positivar derechos humanos en el ordenamiento jurídico internacional, para que así adquieran eficacia jurídica, aparece de este modo como la técnica más adecuada. Sin embargo, discrepo de ella básicamente por la propia inseguridad que ofrece un derecho internacional construido en base a tratados y convenciones, y regulado por órganos, como las Naciones Unidas, cuyas resoluciones no tienen el respaldo de un poder coactivo. La invasión de los Estados Unidos a Irak el año 2003, en marco de la denominada guerra contra el terrorismo, es solo una pequeña muestra de cómo el derecho internacional es vulnerado con consecuencias casi inocuas para el Estado transgresor ${ }^{27}$. Mucho menos dańino resulta -para Estados poderosos dentro del contexto globalno suscribirse a un tratado o a una convención que regule la necesidad de respeto al derecho a la libre expresión y opinión de sus ciudadanos. Es por ello que Habermas, con razón, desconfía del derecho internacional como mecanismo de aseguramiento de derechos fundamentales ${ }^{28}$, señalando, además, que la esperanza de la existencia de un orden jurídico internacional basado en la obligatoriedad de respeto del mismo es aún lejana ${ }^{29}$.

Sin embargo, el sistema regional de protección a los derechos humanos, en el caso de La última tentación de Cristo, funcionó. La legislación interna del Estado chileno se adecuó de una forma tal que se respetara el contenido del artículo 13 de la Convención Interamericana de Derechos

26 “(...) allí donde los derechos humanos son protegidos en la actualidad, existe aquel primer nivel de derecho mundial (...) un derecho privado internacional. Se trata de un derecho que puede en su esencia, ser común a todas las culturas del mundo mientras que su imposición ocurre a través de los Estados singulares ('racionalmente'). Se trata paradójicamente, de un derecho mundial nacional” HöFfe (2010) 33.

27 Habermas (2000-a) 154.

28 "Sin la existencia de un tribunal internacional y sin un poder supraestatal capaz de imponer sanciones, el derecho internacional no puede ser reclamado ni aplicado del mismo modo que el derecho interno de los Estados". Habermas, Jürgen (1999) "El Estado nacional europeo. Sobre el pasado y el futuro de la soberanía y la ciudadanía". En J. Habermas, La inclusión del otro. Estudios de teoría política, trad. Juan Carlos Velasco y Gerard Vilar. Barcelona: Paidós, p. 104.

29 “(...) está todavía lejos de alcanzarse el objetivo de un derecho cosmopolita efectivamente institucionalizado" Habermas (2000-a) 153. O. Höffe también aboga por la creación de un orden de justicia política de carácter mundial, marcadamente kantiano. HöFfe (2010) 29 y ss. 
Humanos. Pero el problema de la incorporación de un determinado derecho al orden positivo para que cobre la suficiente fuerza jurídica es todavía un misterio. ¿Acaso un derecho -subjetivo o colectivo- será un límite para el Estado solo cuando está positivado y se transforme en una regla escrita que tanto los habitantes del mismo Estado como los demás Estados y/u organismos internacionales están en pie de demandar su cumplimiento?

Ya señalé que internamente el derecho a la libertad de expresión se traduce en un derecho de participación en los mecanismos comunicativoinformales de la compleja estructura intersubjetiva, y por lo tanto, no es necesario positivarlo en un Estado de Derecho democrático; pero en el plano internacional al parecer, es necesaria su entrada al ordenamiento jurídico positivo, como cualquier otro derecho subjetivo bajo el planteamiento de Höffe, para que exista una especie de "garantía de respaldo" de que efectivamente los Estados respetarán tal derecho. Lamentablemente, en el escenario actual, que así sea dependerá en gran medida de la disposición de los Estados para respetarlo tanto en su faz jurídica objetiva como subjetiva.

Es por ello que, y como corolario de la exposición propuesta, concluyo que la libertad de expresión constituye sin dudas un límite al poder estatal en la esfera interna de tal poder, en cuanto tal poder se desarrolle bajo un rígido esquema democrático procedimental, como el que propone Habermas. En cuanto a la esfera externa -amparada bajo las normas del Derecho Internacional-, inclusive la teoría parece dudar de la misma teoría y, por ello, de la validez del imperativo normativo. Así, la subjetividad del derecho ("derecho humano") parece ser un canon moral obligatorio incluso para una comunidad de Estados, pero su positivación parece necesaria para garantizar cualquier derecho vulnerado dentro de los límites estatales. El parece se desliga de la falta de coacción a la inobservancia de las normas internacionales, produciendo la duda en su efectividad.

En definitiva, el derecho a la libertad de expresión tiene un alcance bifronte: como libertad negativa y libertad de participación dentro de las fronteras del Estado democrático; mientras que en el espectro internacional solo es vinculante su defensa como libertad negativa, o sea, su defensa como derecho fundamental (en caso de que esté positivado) o como la categoría jurídico-moral de derecho humano, en caso contrario.

Sin embargo, tal propuesta teórica parece impracticable dentro de los cánones democráticos actuales, debido a los vaivenes prácticos que supone el ejercicio democrático del poder. Empero, considero que el aporte filosófico de Habermas proyecta un hilo normativo interesante a la construcción práctica del ejercicio de la democracia misma al integrar la comunicación (discurso) y sus reglas a la participación ciudadana, equiparándolas e incluso instaurando la fuente de obligatoriedad de una norma positiva en la autodeterminación ciudadana. Y la libertad de expresión, 
como derecho, es clave para lograr el cometido de una sociedad discursiva y altamente participativa.

\section{BIBLIOGRAFÍA}

- Alexy, Robert (2004) "Una concepción teórico-discursiva de la razón práctica”. En R. Alexy, El concepto y la validez del derecho, trad. Jorge M. Seña, pp. 131-157. Barcelona: Gedisa Editorial.

- Beade, Ileana P. (2009), "Consideraciones acerca de la concepción kantiana de la libertad en sentido político", Revista de Filosofía 65, pp. 25-41, doi: 10.4067/S0718-43602009000100002. [fecha de acceso: abril 12, 2011].

- Berlin, Isaiah (2004) "Dos Conceptos de Libertad". En Sobre la Libertad. Ed. H. Hardy, y Trad. J. Bayón, 205-255. Madrid: Alianza Editorial.

- Duchacek, Ivo (1976) Derechos y libertades en el mundo actual, trad. Octavio Monserrat Zapater. Madrid: Instituto de Estudios Políticos.

- González Morales, Felipe (2006) "Censura judicial y libertad de expresión: Sistema interamericano y derecho chileno". En Libertad de Expresión en Chile, ed. Felipe González, pp. 11-54. Santiago: Facultad de Derecho de la Universidad Diego Portales.

- Habermas, Jürgen (1999) "El Estado nacional europeo. Sobre el pasado y el futuro de la soberanía y la ciudadanía". En J. Habermas, La inclusión del otro. Estudios de teoría politica, trad. Juan Carlos Velasco y Gerard Vilar, pp. 81-105. Barcelona: Paidós.

- Habermas, Jürgen (2000-a) "Acerca de la legitimación basada en derechos humanos". En J. Habermas, La constelación posnacional. Ensayos Políticos, trad. Pere Fabra et al., pp. 147-166. Barcelona: Paidós.

- Habermas, Jürgen (2000-b) "La constelación posnacional y el futuro de la democracia”. En J. Habermas, La constelación posnacional. Ensayos Políticos, trad. Pere Fabra et al., pp. 81-146. Barcelona: Paidós.

- Habermas, Jürgen (2005) "Política deliberativa". En J. Habermas, Facticidad y Validez. Sobre el derecho y el Estado democrático de derecho en términos de teoría del discurso, $4^{a}$ edición, trad. Manuel Jiménez Redondo, pp. 363-406. Madrid: Trotta.

- Habermas, Jürgen (2010) "The concept of human dignity and the realistic utopia of human rights" Methaphilosophy v. 41-4, pp. 464480 .

- Höffe, Otfried (2003) "Estrategias de la Justicia Política. Una visión panorámica”. En O. Höffe, Justicia Política: Fundamentos para una 
filosofía critica del Derecho y del Estado, pp. 177-208. Barcelona, Paidós.

- Höfre, Otfried (2010) La justicia en un mundo globalizado. Santiago: Universidad Adolfo Ibáńez.

- Locke, John (1999) "Ensayo sobre la tolerancia". En Ensayo y Carta sobre la Tolerancia. Trad. Carlos Mellizo, pp. 23-59. Madrid: Alianza Editorial.

- Lovera Parmo, Domingo (2006) "El interés público como estándar. Libertad de Expresión y Vida Privada". En Libertad de Expresión en Chile, ed. Felipe González, pp. 55-96. Santiago: Facultad de Derecho de la Universidad Diego Portales.

- Nussbaum, Martha C. (2007) Las Fronteras de la Justicia. Trad. Ramón Villa Vernis y Albino Santos Mosquera. Barcelona, Paidós.

- Rawls, John (2004) Teoría de la Justicia. 2a ed. en español. Trad. María Dolores González. México D.F.: Fondo de Cultura Económica.

- Zúñiga Fajuri, Alejandra (2006) "La libre formación del pensamiento en el caso 'La Última Tentación de Cristo". En Libertad de Expresión en Chile, ed. Felipe González, pp. 285-318. Santiago: Facultad de Derecho de la Universidad Diego Portales. 